\title{
Síndrome De Guillain-Barré Abrindo Quadro De Lúpus Eritematoso Sistêmico: Relato De Caso
}

\author{
Barbisan, C.W.; Dutra, P.L.; Kretzer, S.S.; Dal Molin, R.K.; Victorino, J.A.; \\ Gomes, E.C.;
}

Apresentador: Paula Leite Dutra

\section{Resumo}

Introdução: Síndrome de Guillain-Barré (SGB) e Lúpus eritematoso sistêmico (LES) são doenças com componentes auto-imunes bem estabelecidos. Relatamos um caso em que a SGB foi a primeira manifestação do LES. Método: Relato de caso. Resultados: Mulher de 26 anos com alopecia e catarata vem à emergência referindo astenia, parestesia de membros inferiores e febre, além de artralgias. Exames laboratoriais evidenciaram anemia, leucopenia, trombocitopenia e hormônio tireoestimulante (TSH) elevado. Paciente evoluiu com parestesias também em membros superiores associada à diminuição de sensibilidade vibratória e, posteriormente, arreflexia nos quatro membros. Alguns dias após, passou a apresentar alterações visuais, hipoestesia cervical e de face, disestesias e déficit difuso de força muscular, chegando à força grau zero nos quatro membros. Marcadores inflamatórios negativos, à exceção do fator anti-nuclear (FAN) que apresentou padrão pontilhado grosso e título 1:1280. Análise do líquor evidenciou dissociação proteico- citológica. Iniciada, neste momento, infusão de imunoglobulina para tratamento de SGB com base na evolução dos sintomas. Houve pouca melhora clínica, evoluindo com dispnéia, disfagia e retenção urinária. Pela história compatível e preenchendo critérios clínicos para tal, diagnosticou-se LES, sendo instituída pulsoterapia com melhora lenta do quadro, porém progressiva. Realizada eletroneuromiografia que evidenciou comprometimento em tronco de nervos periféricos, polineuropatia sensitiva e motora primariamente desmielinizante, compatível com SGB. Completou tratamento com ciclos de ciclofosfamida. Apresentou recuperação gradual de força, recebendo alta hospitalar com força grau 4 em extremidades distais e grau 3 em extremidades proximais. Conclusões: Polineuropatia desmielinizante é uma complicação muito rara do LES, porém deve-se sempre considerá-la como fator etiológico da SGB. A relação entre as duas doenças ainda não foi bem estabelecida, existindo poucos relatos na literatura, especulando-se que o ponto de intersecção seja o processo imunomediado.

\section{Referência:}

Barbisan, C.W.; Dutra, P.L.; Kretzer, S.S.; Dal Molin, R.K.; Victorino, J.A.; Gomes, E.C.;. Síndrome De Guillain-Barré Abrindo Quadro De Lúpus Eritematoso Sistêmico: Relato De Caso. In: II Congresso Brasileiro de Medicina Hospitalar - II CBMH [= Blucher Medical Proceedings, vol.1, num.5] São Paulo: Editora Blucher, 2014. p.49

DOI 10.5151/medpro-II-cbmh-044 